\title{
Avaliação da Estabilidade, Segurança, Eficácia e Aceitação do Produto "Creme Protetor para a Pele Luva Química Grupo 3 Regeneração"
}

\author{
Nathalia P. Barbosa, Giselle V. G. Lopes, Patrícia A. Moreira, Adriana A. \\ Carvalho \& Christiane S. Almeida
}

O objetivo do estudo é avaliar a estabilidade, a segurança e a eficácia de um creme protetor para as mãos em aerossol, a fim de verificar se o produto apresenta todas as características necessárias para ser apresentado ao mercado consumidor e se atende aos requisitos técnicos para ser validado pelo Ministério do Trabalho e ainda, se a inovação proposta em formulação aerossol melhora a utilização do produto. Os ensaios comprovaram que o Creme Protetor não é alergênico, não é irritante, é classificado como Grupo 3, e ainda apresenta as características necessárias para ser apresentado ao mercado consumidor.

Palavras-chave: EPI; creme de proteção; luva química.

The objective of the study is to evaluate the stability, safety and efficacy of an aerosol hand cream in order to verify that the product has all the necessary characteristics to be presented to the consumer market and meets the technical requirements to be validated by the and if the proposed innovation in aerosol formulation improves the use of the product. The tests showed that Protective Cream is not allergenic, is not irritating, is classified as Group 3, and still presents the necessary characteristics to be presented to the consumer market.

Keywords: PPE; protective cream; chemical glove. 


\section{Introdução}

Dermatose ocupacional (DO) é toda alteração da pele, mucosas e anexos direta ou indiretamente causada, mantida ou agravada por tudo aquilo que seja utilizado na atividade profissional ou exista no ambiente de trabalho. São motivadas por agentes físicos, químicos e biológicos decorrentes da exposição ocupacional e das condições de trabalho. São responsáveis por desconforto, dor, coceira, queimação e outros sintomas que geram até a perda do cargo no trabalho ${ }^{1}$.

A doença ocupacional no Brasil é de grande importância por seus aspectos políticos e sociais, de tal maneira que quatro ministérios estão envolvidos em seu controle: Trabalho, Justiça, Saúde e Previdência Social. A dermatose ocupacional é considerada uma das principais doenças profissionais, sendo a dermatite de contato responsável por $80 \%$ dos $\operatorname{casos}^{1,14}$.

Em países industrializados, as DOs correspondem a, aproximadamente, $60 \%$ das doenças ocupacionais. No Brasil, elas ocorrem principalmente em trabalhadores da construção civil e das indústrias metalúrgicas, sendo que estas têm maiores incidências em empresas de pequeno porte, onde, muitas vezes, não são utilizados os Equipamentos de Proteção Individual (EPIs) adequados para tal ambiente de trabalho, ou são utilizados de forma incorreta ${ }^{1,16}$.

Cerca de $90 \%$ dos casos de DOs apresentam a mão como local mais acometido, sendo a dermatite de contato irritativa o tipo mais comum. Nesses casos, o trabalho em ambiente úmido e a exposição a agentes químicos e físicos contribuem para o início da dermatite ${ }^{14,21}$.

Os cremes/géis de proteção ou "barreira" são projetados para fornecer uma camada protetora entre a pele e as substâncias nocivas. Eles são um dos meios clássicos de proteção da pele contra produtos químicos do meio ambiente e existiram há 50 anos. São, geralmente, formulados para repelir óleo, graxa, tinta e solventes, ou produtos à base de água, tais como ácidos fracos, alcalinos e fluidos de corte de metais ${ }^{10}$. Nesse sentido, o creme protetor constitui produto cosmético em forma de EPI, destinado à proteção da pele do trabalhador contra agentes químicos externos predefinidos. O produto possibilita a formação de uma película protetora que evita a agressão e a perda da integridade da superfície cutânea ${ }^{3}$.

Entre os cremes para a pele, podem encontrar-se dois tipos de produtos para proteção das mãos: cremes de proteção de barreira ou cremes de barreira e cremes de reparação de barreiras, que são usados para prevenir o efeito irritante, causado pela exposição ocupacional e são recomendados para aplicação antes e durante o trabalho. Alguns autores os chamam de cremes pré-trabalho ${ }^{12,27,28 .}$ Eles também foram chamados de "luvas invisíveis", mas o termo "cremes protetores de pele" é mais apropriado"

A função do creme protetor é inibir ou atrasar a penetração cutânea de substâncias que podem ter efeitos deletérios no momento do contato com a pele ou induzir efeitos sistêmicos devido à absorção percutânea. Os cremes de proteção são, portanto, usados para reduzir o efeito irritante das substâncias, prevenindo dermatite de contato irritante ${ }^{19}$.

Da mesma forma que ocorre com outros produtos que promovem a saúde e o bem-estar do consumidor, produtos cosméticos podem, ocasionalmente, apresentar reações adversas aos usuários, decorrentes de fatores individuais ou uso inadequado do produto ${ }^{21,22}$. Sendo assim, os ensaios biológicos para avaliação de segurança, estabilidade e eficácia devem preceder à disponibilidade do cosmético ao mercado ${ }^{6}$.

Diante do exposto, foi desenvolvido um produto com formulação inovadora em forma de aerossol ("Creme Protetor Para a Pele Luva Química Grupo 3 Regeneração"), visando facilitar a aplicação e evitar o uso incorreto do creme protetor pelos trabalhadores ${ }^{16}$.

O objetivo do estudo é avaliar a estabilidade, a segurança, a eficácia e a aceitação do creme protetor desenvolvido, a fim de verificar se o produto apresenta todas as características necessárias para ser apresentado ao mercado consumidor, atendendo às normas e especificações exigidas pelo Ministério do Trabalho para emissão do Certificado de Aprovação (CA) dos Equipamentos de Proteção Individual (EPI). 


\section{Metodologia}

\section{FORMULAÇÃO}

A formulação do creme protetor em aerossol foi desenvolvida em testes de bancada, mas por questões de segredo industrial, não será divulgada neste estudo.

\section{ESTUDO DE ESTABILIDADE ACELERADA}

O estudo de estabilidade acelerada foi realizado segundo as especificações do Guia de Estabilidade de Produtos Cosméticos da ANVISA $^{6}$ adaptado. As amostras do creme protetor foram submetidas a condições menos extremas que o teste de estabilidade preliminar, avaliadas no tempo 0 e aos $7^{\circ}, 15^{\circ}, 30^{\circ} 60^{\circ} \mathrm{e}$ $90^{\circ}$ dias. Foram submetidos aos ciclos de calor em estufa com temperatura de $45{ }^{\circ} \mathrm{C} \pm 2{ }^{\circ} \mathrm{C}$ e frio em geladeira com temperatura $5{ }^{\circ} \mathrm{C} \pm 2{ }^{\circ} \mathrm{C}$ e a exposição luminosa, conforme as recomendações do guia, em que os seguintes parâmetros foram avaliados:

- características organolépticas: aspecto, cor, odor e sabor (quando aplicável);

- características físico-químicas e químicas: $\mathrm{pH}$, viscosidade e densidade;

- características microbiológicas: teste de desafio;

- O estudo utilizou os parâmetros padrões de referência como aspecto creme, cor branco, odor da essência, sem sabor e o pH entre 6,0 e 7,0 conforme na Tabela 1.

Tabela 1. Parâmetros padrões do creme protetor.

\begin{tabular}{|c|c|}
\hline \multicolumn{2}{|c|}{ Parâmetros padrões } \\
\hline Aspecto & Creme \\
\hline Cor & Branco \\
\hline Odor & Característico à essência \\
\hline Sabor & $\mathrm{n} / \mathrm{a}$ \\
\hline $\mathrm{pH}$ & 6,0 a 7,0 \\
\hline
\end{tabular}

*n/a: nenhuma alteração.

\section{SEGURANÇA E EFICÁCIA}

Foram realizadas análises de segurança e de eficácia por empresas terceirizadas brasileiras, empresa A e empresa B. Nas quais, o creme protetor foi testado em relação à sua reação reagente; características físico-químicas; eficácia protetiva; segurança e hipoalergenicidade; irritabilidade dérmica, sistema termorregulador e controle da perda de água transepidermal, métodos que serão descritos abaixo. Todos os métodos são exigidos pela ANVISA e pelo Ministério do trabalho Norma 16276:2017 para o registro do produto em ambos os órgãos, e os resultados devem estar conforme as especificações.

\section{Ação Reagente / Ação Catalisadora}

Ação Catalisadora consiste na determinação do comportamento do creme protetor ou de algum componente, em relação aos agentes químicos, de forma a caracterizar a existência ou não de reação e/ou atividade catalisadora.

$\mathrm{O}$ teste foi realizado, conforme a NR-06, em obediência à Norma 16276:2017 ${ }^{3}$, as normas de Boas Práticas Clínicas (GLP) do Conselho Nacional de Saúde e seus complementares, com as normas internacionais de pesquisas para seres humanos (declaração de Helsinque) e com a Resolução 466, de 13 de Junho de $2012{ }^{11}$.

O procedimento foi realizado, como descrito a seguir:

a. aplicaram-se quantidades uniformes da amostra do creme em lâminas de vidro;

b. colocaram-se as lâminas untadas com amostra do creme em câmaras isoladas, a $\left(22^{\circ} \pm 2^{\circ}\right)$, em contato com as substâncias e misturas das substâncias como agentes externos.

c. as substâncias utilizadas foras as seguintes: água, tolueno, xileno, n-hexano, benzina, querosene, aguarrás, tíner, gasolina, óleo mineral, óleo diesel, acetona, metiletilcetona, percloroetileno, cloreto de metileno, tricloroetileno, clorofórmio, acetato de etila, formaldeído, tinta base óleo, tinta base água, tinta base solvente, pós em geral, negro de fumo, lã de vidro, argamassa, graxas, mistura de areia + cimento + água $(1+2+10)$, mistura água + cal $4 \%(1+1)$, ácido fosfórico diluído $15 \%$, ácido clorídrico diluído a $15 \%$, 
ácido sulfúrico diluído a 15\%, ácido acético diluído a $10 \%$ e hidróxido de sódio diluído a $10 \%$.

A comprovação da barreira protetora do creme é feita pelo laudo de solubilidade, com a seguinte metodologia:

a. em lâminas de vidro de $(2,6 \times 7,6) \mathrm{cm}$, usadas em microscopia, aplicaram-se quantidades uniformes do creme-amostra;

b. estas lâminas untadas com o creme foram colocadas em câmaras isoladas em contato com substâncias ou misturas de substâncias;

c. mantiveram-se 3/4 de cada lâmina submersa e 1/4 de cada lâmina sem contato com o agente químico, mas sim com o ar ambiente e/ou vapor emanado da câmara;

d. fizeram-se as leituras das lâminas de acordo com os seguintes tempos de contato (em minutos): 15, 30, 60, 120, 180, 240;

e. analisou-se em cada uma das leituras anteriores de acordo com a seguinte simbologia:

- NHA: não houve alteração do filme;

- HDF: houve dissolução do filme.

\section{Características Físico-químicas}

Foram determinadas as características físico-químicas ( $\mathrm{pH}$ in natura, perda por dessecação e densidade a 25 ${ }^{\circ} \mathrm{C}$ ), por meio de ensaios laboratoriais, conforme a NR-6, em obediência a Norma ABNT NBR 16276:2017 ${ }^{3}$.

- $\quad$ pH: A determinação potenciométrica do pH é feita de acordo com a Farmacopeia Brasileira, $5^{\text {a }}$ edição 13.

- Perda por dessecação: Este ensaio foi realizado de acordo com os métodos descritos na Farmacopeia Brasileira, $5^{\text {a }}$ edição $0^{13}$, os quais se destinam a determinar a quantidade de substância volátil de qualquer natureza eliminada. Foi utiliza a balança por infravermelho, pesou-se cerca de $1 \mathrm{~g}$ da substância a ser analisada e distribuir o material uniformemente no coletor de alumínio contido dentro do aparelho. Utilizou-se um (1) minuto a $105^{\circ} \mathrm{C}$ e obtivemos o percentual de umidade.
- Densidade a $25{ }^{\circ} \mathrm{C}$ : Este ensaio foi realizado de acordo com os métodos descritos na Farmacopeia Brasileira, $5^{\text {a }}$ edição ${ }^{13}$. Como aparelhagem, foi utilizado um picnômetro limpo e seco, com capacidade de $5 \mathrm{~mL}$, previamente calibrado.

- Classificação da amostra: A classificação da amostra é determinada com o teste de solubilidade - Propriedade água Resistente. Este ensaio consiste em aplicar repetidas vezes o creme de proteção na pele e tem por objetivo detectar possíveis irritações ou indução de sensibilização.

$\mathrm{O}$ teste foi realizado, conforme a NR-06, em obediência a Norma 16276:2017³, as normas de Boas Práticas Clínicas (GLP) do Conselho Nacional de Saúde e seus complementares, com as normas internacionais de pesquisas para seres humanos (declaração de Helsinque) e com a Resolução 466, de 13 de Junho de $2012^{11}$.

O procedimento foi realizado da como descrito a seguir:

a. aplicaram-se quantidades uniformes da amostra do creme em lâminas de vidro;

b. colocou-se a lâmina untada em câmara isolada a $18{ }^{\circ} \mathrm{C}-22^{\circ} \mathrm{C}$ contendo água ou mistura à base de água, de modo que esteja diretamente em contato e submersa;

c. as substâncias utilizadas foram as seguintes: água, tolueno, xileno, n-hexano, benzina, querosene, aguarrás, tíner, gasolina, óleo mineral, óleo diesel, acetona, metiletilcetona, percloroetileno, cloreto de metileno, tricloroetileno, clorofórmio, acetato de etila, formaldeído, tinta base óleo, tinta base água, tinta base solvente, pós em geral, negro de fumo, lã de vidro, argamassa, graxas, mistura de areia + cimento + água $(1+2+10)$, mistura água + cal 4\% $(1+1)$, ácido fosfórico diluído $15 \%$, ácido clorídrico diluído a $15 \%$, ácido sulfúrico diluído a $15 \%$, ácido acético diluído a $10 \%$ e hidróxido de sódio diluído a $10 \%$;

d. avaliou-se o comportamento da amostra do creme a cada $30 \mathrm{~min}$, durante o período de $240 \mathrm{~min}$.

A comprovação da barreira protetora do creme é feita pelo laudo de solubilidade, com a seguinte metodologia: 
a. em lâminas de vidro de $(2,6 \times 7,6) \mathrm{cm}$, usadas em microscopia, aplicaram-se quantidades uniformes do creme-amostra;

b. estas lâminas untadas com o creme foram colocadas em câmaras isoladas em contato com substâncias ou misturas de substâncias;

c. mantiveram-se 3/4 de cada lâmina submersa e 1/4 de cada lâmina sem contato com o agente químico, mas sim com o ar ambiente e/ou vapor emanado da câmara;

d. fizeram-se as leituras das lâminas de acordo com os seguintes tempos de contato (em minutos): 15, 30, 60, 120, 180, 240;

e. analisou-se em cada uma das leituras anteriores de acordo com a seguinte simbologia:

- NHA: não houve alteração do filme;

- HDF: houve dissolução do filme.

\section{Eficácia Protetiva}

O teste de eficácia protetiva é realizado de acordo com o ensaio de barreira protetora frente a ácidos e bases, de acordo com a Portaria $n^{\circ} 26$ de Dezembro/94 da Secretaria de Segurança e Saúde do Trabalhador do Ministério do Trabalho 24, em obediência a Norma ABNT NBR 16276:2017 ${ }^{3}$.

Consiste em diluir previamente as substâncias isoladas de caráter ácido ou básico em água deionizada na diluição desejada, considerando o critério da massa do ácido ou da base por volume de água $(\mathrm{m} / \mathrm{v})$.

O procedimento foi realizado da como descrito a seguir:

a. aplicou-se uma quantidade uniforme da amostra do creme em lâminas de vidro;

b. colocaram-se as lâminas untadas em câmaras isoladas a $18{ }^{\circ} \mathrm{C}-22{ }^{\circ} \mathrm{C}$, contendo solventes orgânicos ou mistura à base de solventes orgânicos, de modo que estejam diretamente em contato e submersas;

c. os solventes utilizados foram os seguintes: ácido fosfórico diluído a $15 \%$, ácido clorídrico diluído a $15 \%$, ácido sulfúrico diluído a $15 \%$, ácido acético a $10 \%$ e hidróxido de sódio diluído a $10 \%$;

d. avaliaram-se os comportamentos da amostra do creme a cada $30 \mathrm{~min}$, durante o período de $240 \mathrm{~min}$.
A comprovação da barreira protetora do creme é feita pelo laudo de solubilidade, com a seguinte metodologia:

a. em lâminas de vidro de $(2,6 \times 7,6) \mathrm{cm}$, usadas em microscopia, aplicaram-se quantidades uniformes da amostra do creme;

b. estas lâminas untadas com o creme foram colocadas em câmaras isoladas em contato com substâncias ou misturas de substâncias;

c. mantiveram-se 3/4 de cada lâmina submerso e 1/4 de cada lâmina sem contato com o agente químico, mas sim com o ar ambiente e/ou vapor emanado da câmara;

d. fizeram-se as leituras das lâminas de acordo com os seguintes tempos de contato (em minutos): 15, 30, 60, 120, 180, 240;

e. analisou-se em cada uma das leituras anteriores a seguinte simbologia:

- NHA: não houve alteração do filme;

- HDF: houve dissolução do filme.

\section{Teste de Hipoalergenicidade}

Realizou-se o teste de Hipoalergenicidade e Segurança Cosmética de Produto Químico, por meio de estudos de compatibilidade cutânea de irritação primária acumulada, sensibilização e fotossensibilização, de acordo com a Portaria $n^{\circ} 26$ de Dezembro/94 da Secretaria de Segurança e Saúde do Trabalhador do Ministério do Trabalho 24, em obediência a Norma ABNT NBR 16276:2017 ${ }^{3}$.

- Avaliação de Irritabilidade (Teste HET-CAM): O objetivo do ensaio é avaliar semiquantitativamente o potencial irritante do Creme Protetor sobre a membrana corioalantoide de ovo embrionado de galinha, no décimo dia de incubação. O ensaio é baseado na observação dos efeitos irritantes (hiperemia, hemorragia e coagulação), após 5 minutos da aplicação do produto, puro ou diluído, sobre a membrana corioalantoide. Obtém-se uma escala que considera os fenômenos observados. Os tensoativos foram testados diluídos $(0,25 \%$ a $2 \%)$. Foram utilizados ovos SPF, fertilizados, de galinha da raça Leghorn, incubados por 10 dias a temperatura de $38^{\circ} \mathrm{C} \pm 5^{\circ} \mathrm{C}$ e umidade relativa de aproximadamente 
$70 \%$. A interpretação dos resultados é seguida de acordo com os significados dispostos na Tabela 2.

- Avaliação da Citoxidade (Teste Red Blood Cell System): O método foi desenvolvido pela empresa B e a descrição não é permitida, entretanto a empresa garante que está conforme as especificações da ANVISA. A interpretação dos resultados é seguida de acordo com os índices da Tabela 3.

- Avaliação da Sensibilidade Cutânea (Patch Test): A condição requerida é a Ausência de Reação Alérgica após a fase de desafio.

- Avaliação da Fotossensibilidade Cutânea (PATCH TEST/ Exposição aos raios UV): A condição requerida é a Ausência de Reação Alérgica após exposição aos raios UV.

Tabela 2. Interpretação dos resultados da Avaliação de Irritabilidade

\begin{tabular}{|c|c|}
\hline Escores & Resultado \\
\hline $0,0-0,9$ & Não irritante \\
\hline $1,0-4,9$ & Fraco ou levemente irritante \\
\hline $5,0-9,9$ & Moderadamente irritante \\
\hline $10,0-21,0$ & Forte ou severamente irritante \\
\hline
\end{tabular}

Tabela 3. Interpretação dos resultados da Avaliação da Citoxidade

\begin{tabular}{|c|c|}
\hline Escores & Resultado \\
\hline$>100$ & Não irritante \\
\hline$\geq 10$ & Irritação leve \\
\hline$\geq 1$ & Moderadamente irritante \\
\hline$\geq 0,1$ & Forte ou severamente irritante \\
\hline$<0,1$ & Irritante máximo \\
\hline
\end{tabular}

\section{Teste de Irritabilidade Dérmica}

Realizou-se o teste de Irritabilidade Dérmica/Efeito Agudo - Dose simples de Creme sobre a pele de coelhos albinos, de acordo com as prescrições do:

a. "Manual Técnico do Instituto Nacional de Controle Qualidade em Saúde" 14;

b. "Manual de Ensaios Toxicólogos in Vivo" 9 .
No dia anterior à aplicação do produto químicoteste, os pelos da região dorsal do tronco dos animais foram depilados. Escolheram-se quatro locais de ensaios adjacentes de aproximadamente $2,5 \mathrm{~cm}^{2}$ cada, sendo duas áreas para aplicação da amostra e duas para controle. Uma das áreas para o controle e outra para amostra foi submetida à abrasão, escarificada.

As amostras do produto químico foram aplicadas sobre as duas áreas, uma das quais escarificada, e cobertas com gaze e fita crepe. A duração da exposição foi de vinte e quatro (24) horas. Ao final, retiraram-se os corpos de prova e lavou-se com água deionizada.

\section{Avaliação do sistema termorregulador}

A avaliação do sistema termorregulador consiste na avaliação do sistema termorregulador de animais de laboratório, durante ensaios de aplicação e de contato direto de creme protetor com a pele, que ateste a não interferência no sistema termorregulador humano.

Foi realizada a avaliação do sistema termorregulador de animais de laboratório, durante ensaios de aplicação e de contato direto do creme protetor com a pele, obedecendo aos procedimentos técnicos na Norma Brasileira NBR 16276:20173, que ateste a não interferência no sistema termorregulador humano (Portaria $n^{\circ}$ 452/2014 - Anexo II - F2) ${ }^{25}$.

No procedimento, utilizaram-se cinco (5) animais adultos, hígidos, da espécie Coelho Albino Neozelandês, pesando entre 3,40 e 4,60 quilos. Mantiveram-se os animais em gaiolas individuais durante todo o período de teste, à temperatura de $24^{\circ} \mathrm{C}$ a $27^{\circ} \mathrm{C}$, e umidade relativa do ar entre $55 \%$ e $70 \%$.

No dia anterior à aplicação do creme protetor de teste, depilaram-se os pelos da região dorsal do tronco do animal. Escolheram-se quatro locais de ensaios adjacentes de aproximadamente $2,5 \mathrm{~cm}^{2}$ cada, sendo duas áreas para aplicação, da amostra e duas para controle. Uma das áreas para o controle e outra para amostra submeteu-se à abrasão, escarificadas.

Aplicaram-se as amostras de creme sobre duas áreas depiladas $\left(2,5 \mathrm{~cm}^{2}\right)$ de cinco coelhos albinos, e cobertas com gaze e fita crepe. Com duração de contato do creme de $10 \mathrm{~h}$. Neste período, de hora em hora, tomaram-se 
medições de temperatura corporal, usando-se a via retal, com termômetro plástico com sensibilidade de $0,1{ }^{\circ} \mathrm{C}$.

Anotaram-se os dados de temperatura ambiente $\left(24{ }^{\circ} \mathrm{C}\right.$ $-25^{\circ} \mathrm{C}$ ) e umidade relativa do ar entre $55 \%$ a $60 \%$.

Utilizaram-se os seguintes critérios para controles da temperatura:

a. faixa normal: de $38,3{ }^{\circ} \mathrm{C}$ a $39,4{ }^{\circ} \mathrm{C}$;

b. hipotermia: Inferior a $38,1^{\circ} \mathrm{C}$;

c. hipertermia: superior a $39,7^{\circ} \mathrm{C}$.

\section{Estudo clínico comparativo, aberto, aleatorizado e controlado da perda de água transepidermal após aplicação de produto tópico}

Este estudo foi conduzido de acordo com os princípios da Declaração de Helsinque, as solicitações regulatórias aplicáveis, incluindo a Resolução CNS $n^{\circ}$ 466/12, e no espírito das Boas Práticas Clínicas (Documento das Américas e ICH E6: Good Clinical Practice) ${ }^{11}$.

Os participantes foram informados do objetivo do estudo, sua metodologia e duração, e dos benefícios, possivelmente, esperados e das restrições ligadas ao estudo. Os que confirmaram seu interesse em participar, assinaram um Termo de Consentimento Livre e Esclarecido.

Foram demarcadas duas áreas de $25 \mathrm{~cm}^{2}$ simétricas na região anterior dos antebraços de 20 participantes. Uma área foi utilizada para aplicação do produto e uma área foi mantida como controle (área sem tratamento), de maneira aleatória. As avaliações foram realizadas através do equipamento Tewameter TM 300 (Courage+Khazaka electronic $\mathrm{GmbH})$ antes da aplicação do produto e após 1,5 horas da aplicação.

Produto e controle foram comparados, em cada tempo, através do teste $\mathrm{t}$ de Student com hipótese bilateral. O participante 011 foi considerado outlier, pelo teste de Grubbs, sendo desconsiderado das análises. O nível de confiança considerado nas análises comparativas foi de 95\%. Os softwares utilizados foram o XLSTAT 2017 e o MINITAB ${ }^{14}$.

\section{ANÁLISE SENSORIAL}

O teste de análise sensorial foi realizado com colaboradores de duas empresas, com autorização da comissão de ética, com o número de parecer 1.977.667. Foram selecionados quatro funcionários da empresa para utilizar o creme protetor, durante um mês, com acompanhamento semanal dos resultados.

Os usuários foram recomendados sobre a forma de aplicação da Creme Protetor e de como seria a avaliação das características do produto. Para certificação das opiniões e grau de satisfação a cerca do produto utilizouse de questionário padronizado que podem ser observados na Tabela 4 em que foram avaliados parâmetros, como: espalhabilidade, aparência, hidratação, absorção, sensorial na Aplicação, recuperação das fissuras após $24 \mathrm{~h}$, recuperação das fissuras após 48h, recuperação das fissuras após 72h, recuperação das fissuras após $96 \mathrm{~h}$ e perfume do produto.

Tabela 4. Questionário padronizado para avaliação do creme protetor.

\begin{tabular}{|c|c|c|c|c|c|c|c|c|c|c|}
\hline Parâmetro & \multicolumn{7}{|c|}{ Nota } \\
\hline Espalhabilidade & 1 & 2 & 3 & 4 & 5 & 6 & 7 & 8 & 9 & 0 \\
\hline Aparência & 1 & 2 & 3 & 4 & 5 & 6 & 7 & 8 & 9 & 0 \\
\hline Hidratação & 1 & 2 & 3 & 4 & 5 & 6 & 7 & 8 & 9 & 0 \\
\hline Absorção & 1 & 2 & 3 & 4 & 5 & 6 & 7 & 8 & 9 & 0 \\
\hline $\begin{array}{c}\text { Sensorial na } \\
\text { Aplicação }\end{array}$ & 1 & 2 & 3 & 4 & 5 & 6 & 7 & 8 & 9 & 0 \\
\hline $\begin{array}{c}\text { Recuperação das } \\
\text { fissuras após 24h }\end{array}$ & 1 & 2 & 3 & 4 & 5 & 6 & 7 & 8 & 9 & 0 \\
\hline $\begin{array}{c}\text { Recuperação das } \\
\text { fissuras após 48h }\end{array}$ & 1 & 2 & 3 & 4 & 5 & 6 & 7 & 8 & 9 & 0 \\
\hline $\begin{array}{c}\text { Recuperação das } \\
\text { fissuras após 72h }\end{array}$ & 1 & 2 & 3 & 4 & 5 & 6 & 7 & 8 & 9 & 0 \\
\hline $\begin{array}{l}\text { Recuperação das } \\
\text { fissuras após 96h }\end{array}$ & 1 & 2 & 3 & 4 & 5 & 6 & 7 & 8 & 9 & 0 \\
\hline Perfume do produto & 1 & 2 & 3 & 4 & 5 & 6 & 7 & 8 & 9 & 0 \\
\hline
\end{tabular}

\section{Resultados e Discussões}

\section{ESTUDO DE ESTABILIDADE ACELERADA}

Na Tabela 5, encontram-se os resultados do estudo de estabilidade acelerada. 
Tabela 5. Resultado do estudo de estabilidade acelerada para o Creme Protetor Para a Pele Luva Química Grupo 3 Regeneração.

\begin{tabular}{|c|c|c|c|c|c|c|}
\hline Características & Zero & $7^{\circ}$ dia & $15^{\circ}$ dia & $30^{\circ}$ dia & $60^{\circ}$ dia & $90^{\circ}$ dia \\
\hline Aspecto & De acordo & De acordo & De acordo & De acordo & De acordo & De acordo \\
\hline Cor & De acordo & De acordo & De acordo & De acordo & De acordo & De acordo \\
\hline Odor & De acordo & De acordo & De acordo & De acordo & De acordo & De acordo \\
\hline Sabor & $\mathrm{n} / \mathrm{a}^{*}$ & $\mathrm{n} / \mathrm{a}^{*}$ & $\mathrm{n} / \mathrm{a}^{*}$ & $\mathrm{n} / \mathrm{a}^{*}$ & $\mathrm{n} / \mathrm{a}^{*}$ & $\mathrm{n} / \mathrm{a}^{*}$ \\
\hline $\mathrm{pH}$ & 6,1 & 6,1 & 6,5 & 6,5 & 6,4 & 6,4 \\
\hline Viscosidade & De acordo & De acordo & De acordo & De acordo & De acordo & De acordo \\
\hline $\begin{array}{l}\text { Contagem de micro-or- } \\
\text { ganismos mesófilos totais } \\
\text { aeróbicos }\end{array}$ & - & - & & - & - & $\begin{array}{l}<1,0 \times 101 \\
\quad \mathrm{UFC} / \mathrm{g}\end{array}$ \\
\hline $\begin{array}{c}\text { Pseudomas aeruginosa em } \\
1 \mathrm{~g} \text { ou } 1 \mathrm{~mL}\end{array}$ & - & - & - & - & - & Ausência \\
\hline $\begin{array}{c}\text { Staphylococcus aureus em } \\
1 \mathrm{~g} \mathrm{ou} 1 \mathrm{~mL}\end{array}$ & - & - & - & - & - & Ausência \\
\hline $\begin{array}{l}\text { Coliformes totais e fecais } \\
\qquad 1 \mathrm{~g} \text { ou } 1 \mathrm{~mL}\end{array}$ & - & - & - & - & - & Ausência \\
\hline
\end{tabular}

*n/a: nenhuma alteração.

De acordo com os resultados apresentados na Tabela acima, o Creme Protetor está conforme as especificações estabelecidas pelo Guia de Estabilidade (ANVISA) ${ }^{6}$ e o controle de qualidade / microbiológico está conforme a Resolução vigente RDC $481 / 99^{8}$ dentro do prazo especificado, que são dois anos.

Segundo a ANVISA ${ }^{6}$, a empresa é responsável por avaliar a estabilidade de seus produtos, antes de disponibilizá-los ao consumo, requisito fundamental à qualidade e à segurança desses. Produtos expostos ao consumo e que apresentem problemas de estabilidade organoléptica, físico-química e ou microbiológica, além de descumprirem os requisitos técnicos de qualidade podem, ainda, colocar em risco a saúde do consumidor configurando infração sanitária. O estudo de estabilidade fornece indicações sobre o comportamento do produto, em determinado intervalo de tempo, frente a condições ambientais a que possa ser submetido, desde a fabricação até o término da validade.

\section{SEGURANÇA E EFICÁCIA}

\section{Ação Reagente / Ação Catalisadora}

Os resultados dos ensaios de ação reagente/ catalisadora encontram-se na Tabela 6. Os contatos entre o creme protetor e os produtos químicos mostraram que, durante 240 minutos, não houve alterações (NHA):
a. variação de temperatura;
b. alteração de cor;
c. modificação do aspecto e da consistência do creme;
d. emissões gasosas;
e. alteração de homogeneidade do filme.

O creme protetor experimentado não mostrou ação reagente nem ação catalisadora frente aos produtos químicos testados de acordo com a norma NBR 16276.

Na Tabela 6, constam os resultados dos ensaios de ação reagente/catalisadora do creme protetor. 
Tabela 6. Resultados dos ensaios de ação reagente/catalisadora do creme protetor.

\begin{tabular}{|c|c|c|c|c|c|c|}
\hline \multirow{2}{*}{ Solventes } & \multicolumn{6}{|c|}{ Tempo de Contato (minutos) } \\
\hline & 15 & 30 & 60 & 120 & 180 & 240 \\
\hline Água & NHA & NHA & NHA & NHA & NHA & NHA \\
\hline Tolueno & NHA & NHA & NHA & NHA & NHA & NHA \\
\hline Xileno & NHA & NHA & NHA & NHA & NHA & NHA \\
\hline n-hexano & NHA & NHA & NHA & NHA & NHA & NHA \\
\hline Benzina & NHA & NHA & NHA & NHA & NHA & NHA \\
\hline Querosene & NHA & NHA & NHA & NHA & NHA & NHA \\
\hline Aguarrás & NHA & NHA & NHA & NHA & NHA & NHA \\
\hline Tíner & NHA & NHA & NHA & NHA & NHA & NHA \\
\hline Gasolina & NHA & NHA & NHA & NHA & NHA & NHA \\
\hline Óleo mineral & NHA & NHA & NHA & NHA & NHA & NHA \\
\hline Óleo diesel & NHA & NHA & NHA & NHA & NHA & NHA \\
\hline Acetona & NHA & NHA & NHA & NHA & NHA & NHA \\
\hline Metiletilcetona & NHA & NHA & NHA & NHA & NHA & NHA \\
\hline Percloroetileno & NHA & NHA & NHA & NHA & NHA & NHA \\
\hline Cloreto de metileno & NHA & NHA & NHA & NHA & NHA & NHA \\
\hline Tricloroetileno & NHA & NHA & NHA & NHA & NHA & NHA \\
\hline Clorofórmio & NHA & NHA & NHA & NHA & NHA & NHA \\
\hline Acetato de etila & NHA & NHA & NHA & NHA & NHA & NHA \\
\hline Formaldeído & NHA & NHA & NHA & NHA & NHA & NHA \\
\hline Tinta base óleo & NHA & NHA & NHA & NHA & NHA & NHA \\
\hline Tinta base água & NHA & NHA & NHA & NHA & NHA & NHA \\
\hline Tinta base solvente & NHA & NHA & NHA & NHA & NHA & NHA \\
\hline Pós em geral & NHA & NHA & NHA & NHA & NHA & NHA \\
\hline Negro de fumo & NHA & NHA & NHA & NHA & NHA & NHA \\
\hline Lã de vidro & NHA & NHA & NHA & NHA & NHA & NHA \\
\hline Argamassa & NHA & NHA & NHA & NHA & NHA & NHA \\
\hline Graxas & NHA & NHA & NHA & NHA & NHA & NHA \\
\hline Mistura de areia + cimento + água $(1+2+10)$ & NHA & NHA & NHA & NHA & NHA & NHA \\
\hline Mistura água $+\mathrm{cal} 4 \%(1+1)$ & NHA & NHA & NHA & NHA & NHA & NHA \\
\hline Ácido fosfórico diluído $15 \%$ & NHA & NHA & NHA & NHA & NHA & NHA \\
\hline Ácido clorídrico diluído a $15 \%$ & NHA & NHA & NHA & NHA & NHA & NHA \\
\hline Ácido sulfúrico diluído a $15 \%$ & NHA & NHA & NHA & NHA & NHA & NHA \\
\hline Ácido acético diluído a $10 \%$ & NHA & NHA & NHA & NHA & NHA & NHA \\
\hline Hidróxido de sódio diluído a $10 \%$ & NHA & NHA & NHA & NHA & NHA & NHA \\
\hline
\end{tabular}

NHA: não houve alteração do filme. 


\section{Características Físico-químicas}

Os resultados dos ensaios de caracterização físico-química encontram-se na Tabela 7 . Os resultados apresentados estão conforme a legislação vigente, levando em consideração o fato da formulção ser em aerossol e não apresentar legislação específica.

Tabela 7. Resultados dos ensaios de caracterização físico-química do creme protetor.

\begin{tabular}{|c|c|c|}
\hline Parâmetros & Resultados & $\begin{array}{c}\text { Faixa de trabalho } \\
\text { e/ou LQ }\end{array}$ \\
\hline pH "in natura" & 6,3 & $\begin{array}{c}\text { Faixa de trabalho: } \\
2,0-12,0\end{array}$ \\
\hline $\begin{array}{c}\text { Perda por desse- } \\
\text { cação }\end{array}$ & $82,30 \%$ & LQ: $0,1 \%$ \\
\hline Densidade a $25^{\circ} \mathrm{C}$ & $0,6657 \mathrm{~g} / \mathrm{mL}$ & $\begin{array}{c}\text { Faixa de trabalho: } \\
0,8000-1,4000 \\
\mathrm{~g} / \mathrm{mL}\end{array}$ \\
\hline
\end{tabular}

Os resultados dos ensaios físico-químicos no creme protetor foram aprovados para os parâmetros pH e perda por dessecação. Foi reprovado no parâmetro densidade, situando-se abaixo da faixa de trabalho requerida: $0,8^{-1}, 4 \mathrm{~g} / \mathrm{mL}$ frente aos requesitos exigidos pela Norma ABNT NBR 16276/2017³.

Estudos comprovam que a temperatura é um fator que influencia muito nas características físicas do creme e também o ajuste do $\mathrm{pH}$, pois ambos demonstraram a importância de se ter um creme no pH ideal e armazenado em local adequado para que apresente estabilidade durante o prazo de validade estabelecido ${ }^{22}$. Assim, justifica-se o padrão de $\mathrm{pH}$ do creme protetor desenvolvido estar conforme as especificações.

A perda por dessecação apresenta resultados relativos à umidade do produto, e se tratando de uma formulação cosmética em que a base é água, a umidade é considerada a determinação do teor de água residual presente nas formulações constituindo um índice da qualidade de sua preparação e da garantia de sua conservação ${ }^{30}$. E esta se encontra conforme a especificação vigente.

$\mathrm{O}$ fato de a densidade a $25^{\circ} \mathrm{C}$ não estar conforme a especificação, justifica-se pelo fato da formulação ser em aerossol. A Norma ABNT NBR 16276/2017 refere-se a um creme de proteção e como o produto trata-se de uma formulação em aerossol a densidade não se encontra dentro do padrão, mas está dentro das densidades para aerossol. Tal fato acontece devido os gases que são inseridos para obtenção em aerossol.

\section{Classificação da amostra}

Os resultados dos ensaios de classificação da amostra do creme protetor encontram-se na Tabela 8. A amostra do creme protetor experimentada foi classificada como "Grupo 3/especial". Os cremes de proteção são fabricados em algumas classes: Grupo 1 - água- resistentes: são aqueles que, quando aplicados à pele do usuário, não são facilmente removidos com água; Grupo 2- óleo- resistentes: são aqueles que, quando aplicados à pele do usuário, não são facilmente removíveis na presença de óleo; e Grupo 3-cremes especiais: são aqueles com indicações de uso definidos, especificados pelo fabricante ${ }^{3}$.

A principal característica para a classificação como grupo 3 resulta que o produto desenvolvido é tanto resistente a água quanto a óleo-resistente. Tal fato considera o produto em aerossol desenvolvido com maior espectro de atuação protegendo de forma mais abrangente o trabalhador e prevenindo doenças ocupacionais como as dermatoses ocupacionais 
Tabela 8. Resultados dos ensaios de classificação do creme protetor.

\begin{tabular}{|c|c|c|c|c|c|c|}
\hline \multirow{2}{*}{ Solventes } & \multicolumn{6}{|c|}{ Tempo de Contato (minutos) } \\
\hline & 15 & 30 & 60 & 120 & 180 & 240 \\
\hline Água & NHA & NHA & NHA & NHA & NHA & NHA \\
\hline Tolueno & NHA & NHA & NHA & NHA & NHA & NHA \\
\hline Xileno & NHA & NHA & NHA & NHA & NHA & NHA \\
\hline N-hexano & NHA & NHA & NHA & NHA & NHA & NHA \\
\hline Benzina & NHA & NHA & NHA & NHA & NHA & NHA \\
\hline Querosene & NHA & NHA & NHA & NHA & NHA & NHA \\
\hline Aguarrás & NHA & NHA & NHA & NHA & NHA & NHA \\
\hline Thinner & NHA & NHA & NHA & NHA & NHA & NHA \\
\hline Gasolina & NHA & NHA & NHA & NHA & NHA & NHA \\
\hline Óleo mineral & NHA & NHA & NHA & NHA & NHA & NHA \\
\hline Óleo diesel & NHA & NHA & NHA & NHA & NHA & NHA \\
\hline Acetona & NHA & NHA & NHA & NHA & NHA & NHA \\
\hline Metiletilcetona & NHA & NHA & NHA & NHA & NHA & NHA \\
\hline Percloroetileno & NHA & NHA & NHA & NHA & NHA & NHA \\
\hline Cloreto de metileno & NHA & NHA & NHA & NHA & NHA & NHA \\
\hline Tricloroetileno & NHA & NHA & NHA & NHA & NHA & NHA \\
\hline Clorofórmio & NHA & NHA & NHA & NHA & NHA & NHA \\
\hline Acetato de etila & NHA & NHA & NHA & NHA & NHA & NHA \\
\hline Formaldeído & NHA & NHA & NHA & NHA & NHA & NHA \\
\hline Tinta base óleo & NHA & NHA & NHA & NHA & NHA & NHA \\
\hline Tinta base água & NHA & NHA & NHA & NHA & NHA & $\mathrm{NHA}$ \\
\hline Tinta base solvente & NHA & NHA & NHA & NHA & NHA & NHA \\
\hline Pós em geral & NHA & NHA & NHA & NHA & NHA & NHA \\
\hline Negro de fumo & NHA & NHA & NHA & NHA & NHA & NHA \\
\hline Lã de vidro & NHA & NHA & NHA & NHA & NHA & NHA \\
\hline Argamassa & NHA & NHA & NHA & NHA & NHA & NHA \\
\hline Graxas & NHA & NHA & NHA & NHA & NHA & NHA \\
\hline Mistura de areia + cimento + água $(1+2+10)$ & NHA & NHA & NHA & NHA & NHA & NHA \\
\hline Mistura água + cal 4\% $(1+1)$ & NHA & NHA & NHA & NHA & NHA & NHA \\
\hline
\end{tabular}

NHA: não houve alteração do filme.

\section{Eficácia Protetiva}

Os resultados dos ensaios de eficácia protetiva do creme protetor encontram-se na Tabela 9.
A amostra do creme protetor mostrou eficiente proteção frente aos agentes químicos testados, durante 240 minutos. 
Tabela 9. Resultado dos ensaios de eficácia do creme protetor.

\begin{tabular}{|c|c|c|c|c|c|c|}
\hline \multirow{2}{*}{ Solventes } & \multicolumn{7}{|c|}{ Tempo de Contato (minutos) } \\
\cline { 2 - 7 } & $\mathbf{1 5}$ & $\mathbf{3 0}$ & $\mathbf{6 0}$ & $\mathbf{1 2 0}$ & $\mathbf{1 8 0}$ & $\mathbf{2 4 0}$ \\
\hline Ácido fosfórico diluído a $15 \%$ & NHA & NHA & NHA & NHA & \multirow{2}{*}{ NHA } & NHA \\
\hline Ácido clorídrico diluído a $15 \%$ & NHA & NHA & NHA & NHA & \multirow{2}{*}{ NHA } & \multirow{2}{*}{ NHA } \\
\hline Ácido sulfúrico diluído a $15 \%$ & NHA & NHA & NHA & NHA & \multirow{2}{*}{ NHA } & NHA \\
\hline Ácido acético diluído $10 \%$ & NHA & NHA & NHA & NHA & \multirow{2}{*}{ NHA } & NHA \\
\hline Hidróxido de sódio diluído a $10 \%$ & NHA & NHA & NHA & NHA & \multirow{2}{*}{ NHA } & \multirow{2}{*}{ NHA } \\
\hline
\end{tabular}

NHA: não houve alteração do filme.

\section{Teste de Hipoalergenicidade}

- Avaliação de Irritabilidade (Teste HETCAM): De acordo com a avaliação da irritabilidade (Teste HET-CAM), a amostra do creme protetor obteve o seguinte comportamento:

- hemorragia: ausente/ Escore 0,0;

- lise: ausente/ Escore 0,0;

- coagulação: ausente/ Escore 0,0.

Tais resultados demonstram que o creme protetor não é alergênico. A confirmação da hipoalergênicidade de um produto cosmético, entretanto, só é garantida por meio da realização de estudos de seu potencial de sensibilização e fotoalergia cutânea. Tal fato caracteriza o produto, pois foi formulado de maneira a minimizar possível surgimento de alergia.

- Avaliação da Citotoxidade (Teste Red Blood Cell System): De acordo com a avaliação da citoxidade (Red Blood Cell System), a amostra do creme protetor obteve o seguinte comportamento:

- ausênia de Hemólise;

- desnaturação da Hemoglobina - índice > 100 .
Tal resultado caracteriza que o produto desenvolvido não apresenta riscos citotóxicos e garante ao consumidor que este não promove alterações metabólicas nas células em cultura.

- Avaliação da Sensibilidade Cutânea (Patch Test): Com a realização do teste de sensilbilidade cutânea (PATCH Test) obteve-se a ausência de reação alérgica localizada após a fase de desafio.

- Avaliação da Fotossensibilidade Cutânea (Patch Test/ Exposição aos raios UV): Com a avaliação da fotossensibilidade cutânea, obteve-se a ausência de reação alérgica localizada após a exposição de raios UV.

\section{Teste de Irritabilidade Dérmica}

Os resultados do ensaio de irritabilidade dérmica se encontram no Quadro 1 e Quadro 2. A irritação pode ser definida como intolerância local podendo corresponder a reações de desconforto, variando sua intensidade, desde ardor, coceira e pinicação podendo chegar até a corrosão e destruição do tecido. Todas estas reações se restringem à área em contato direto com o produto ${ }^{7}$. A amostra do creme protetor foi classificada como "não irritante". 
Quadro 1. Resultados dos ensaios de eritema e escaras do creme protetor.

\begin{tabular}{|c|c|c|c|c|c|c|}
\hline \multirow{2}{*}{ Eritema e Escaras } & \multirow{2}{*}{ Leituras } & \multicolumn{5}{|c|}{ Coelhos no $^{\circ}$} \\
\cline { 2 - 7 } & & $\mathbf{1}$ & $\mathbf{2}$ & $\mathbf{3}$ & $\mathbf{4}$ & $\mathbf{5}$ \\
\hline \multirow{3}{*}{ Pele integra } & $01 \mathrm{~h}$ & 0 & 0 & 0 & 0 & 0 \\
\cline { 2 - 7 } & $24 \mathrm{~h}$ & 0 & 0 & 0 & 0 & 0 \\
\cline { 2 - 7 } & $72 \mathrm{~h}$ & 0 & 0 & 0 & 0 & 0 \\
\cline { 2 - 7 } & $7 \mathrm{dd}$ & 0 & 0 & 0 & 0 & 0 \\
\hline \multirow{3}{*}{ Pele escarificada } & $01 \mathrm{~h}$ & 0 & 0 & 0 & 0 & 0 \\
\cline { 2 - 7 } & $24 \mathrm{~h}$ & 0 & 0 & 0 & 0 & 0 \\
\cline { 2 - 7 } & $72 \mathrm{~h}$ & 0 & 0 & 0 & 0 & 0 \\
\cline { 2 - 7 } & $7 \mathrm{dd}$ & 0 & 0 & 0 & 0 & 0 \\
\hline
\end{tabular}

Quadro 2. Resultados dos ensaios de edema do creme protetor.

\begin{tabular}{|c|c|c|c|c|c|c|}
\hline \multirow{2}{*}{ Eritema e Escaras } & \multicolumn{5}{|c|}{ Coeituras } & \multicolumn{5}{|c|}{ Coes nos $^{\circ}$} \\
\hline \multirow{3}{*}{ Pele integra } & $01 \mathrm{~h}$ & 1 & 2 & 3 & 4 & 5 \\
\cline { 2 - 7 } & $24 \mathrm{~h}$ & 0 & 0 & 0 & 0 & 0 \\
\cline { 2 - 7 } & $72 \mathrm{~h}$ & 0 & 0 & 0 & 0 & 0 \\
\cline { 2 - 7 } & $7 \mathrm{dd}$ & 0 & 0 & 0 & 0 & 0 \\
\hline \multirow{3}{*}{ Pele escarificada } & $01 \mathrm{~h}$ & 0 & 0 & 0 & 0 & 0 \\
\cline { 2 - 7 } & $24 \mathrm{~h}$ & 0 & 0 & 0 & 0 & 0 \\
\cline { 2 - 7 } & $72 \mathrm{~h}$ & 0 & 0 & 0 & 0 & 0 \\
\cline { 2 - 7 } & $7 \mathrm{dd}$ & 0 & 0 & 0 & 0 & 0 \\
\hline
\end{tabular}

\section{Avaliação do sistema termorregulador}

Os resultados expressos em graus centígrados, escala Celsius, estão apresentados nas formas de valor médio das (10) medições, valor mínimo e valor máximo e podem ser observados na Tabela 10 .

Os resultados obtidos indicaram que o creme protetor não exerceu nenhuma alteração sobre o sistema termorregulador, nas condições ensaiadas.

Tabela 10. Resultados dos ensaios de avaliação do sistema termorregulador

\begin{tabular}{|c|c|c|}
\hline Médio $\left({ }^{\circ} \mathbf{C}\right)$ & Mínimo $\left({ }^{\circ} \mathbf{C}\right)$ & Máximo $\left({ }^{\circ} \mathbf{C}\right)$ \\
\hline 38,8 & 38,6 & 39,2 \\
\hline
\end{tabular}

Estudo clínico comparativo, aberto, aleatorizado e controlado da perda de água transepidermal após aplicação de produto tópico

Os resultados das análises realisados com o produto tópico podem ser observados na Tabela 11 . O creme protetor promoveu a redução na perda de água transepidermal, evidenciada por alterações significativas do equipamento tewameter, ao nível de significância de 5\%, no tempo uma hora e meia após a aplicação, em relação ao Controle. Tal fato resulta que o creme não permitiu a perda de água da pele o que garante uma maior hidratação da pele, podendo caracterizar o produto como regenerador. 


\section{Resumo Estendido}

Tabela 11. Resultados observados, estatísticas descritivas e resultado da comparação para o produto: 063915-02 e Controle.

\begin{tabular}{|c|c|c|c|c|c|c|c|c|c|}
\hline \multirow[b]{2}{*}{ Participante } & \multicolumn{3}{|c|}{ Creme Protetor } & \multicolumn{3}{|c|}{ Controle } & \multicolumn{3}{|c|}{ 063915-02 - Controle } \\
\hline & T0 & T 1,5 h & $\begin{array}{c}\Delta(\mathrm{T} 1,5 \mathrm{~h}- \\
\quad-\mathrm{T} 0)\end{array}$ & T0 & T 1,5 h & $\begin{array}{c}\Delta(\mathrm{T} 1,5 \mathrm{~h}- \\
\quad-\mathrm{T} 0)\end{array}$ & T0 & T 1,5 h & $\Delta(\mathrm{T} 1,5 \mathrm{~h}-\mathrm{T} 0)$ \\
\hline 001 & 12,2 & 10,9 & $-1,3$ & 10,1 & 9,4 & $-0,7$ & 2,1 & 1,5 & $-0,6$ \\
\hline 002 & 11,9 & 8,6 & $-3,3$ & 9,2 & 8,1 & $-1,1$ & 2,7 & 0,5 & $-2,2$ \\
\hline 003 & 7,7 & 8,1 & 0,4 & 8,1 & 7,5 & $-0,6$ & $-0,4$ & 0,6 & 1,0 \\
\hline 004 & 9,9 & 8,1 & $-1,8$ & 9,9 & 7,7 & $-2,2$ & 0,0 & 0,4 & 0,4 \\
\hline 005 & 11,2 & 9,6 & $-1,6$ & 11,0 & 10,5 & $-0,5$ & 0,2 & $-0,9$ & $-1,1$ \\
\hline 006 & 12,4 & 11,0 & $-1,4$ & 13,5 & 11,1 & $-2,4$ & $-1,1$ & $-0,1$ & 1,0 \\
\hline 007 & 12,9 & 10,4 & $-2,5$ & 11,6 & 11,1 & $-0,5$ & 1,3 & $-0,7$ & $-2,0$ \\
\hline 008 & 10,3 & 8,6 & $-1,7$ & 10,9 & 8,9 & $-2,0$ & $-0,6$ & $-0,3$ & 0,3 \\
\hline 009 & 10,7 & 10,7 & 0,0 & 13,5 & 12,4 & $-1,1$ & $-2,8$ & $-1,7$ & 1,1 \\
\hline 010 & 13,1 & 10,4 & $-2,7$ & 13,6 & 12,0 & $-1,6$ & $-0,5$ & $-1,6$ & $-1,1$ \\
\hline 012 & 12,9 & 11,2 & $-1,7$ & 11,7 & 10,6 & $-1,1$ & 1,2 & 0,6 & $-0,6$ \\
\hline 013 & 11,7 & 10,0 & $-1,7$ & 10,5 & 10,3 & $-0,2$ & 1,2 & $-0,3$ & $-1,5$ \\
\hline 014 & 9,0 & 8,3 & $-0,7$ & 10,6 & 10,5 & $-0,1$ & $-1,6$ & $-2,2$ & $-0,6$ \\
\hline 015 & 12,2 & 11,1 & $-1,1$ & 10,8 & 10,4 & $-0,4$ & 1,4 & 0,7 & $-0,7$ \\
\hline 016 & 12,5 & 10,7 & $-1,8$ & 11,9 & 11,5 & $-0,4$ & 0,6 & $-0,8$ & $-1,4$ \\
\hline 017 & 9,7 & 8,2 & $-1,5$ & 10,5 & 10,2 & $-0,3$ & $-0,8$ & $-2,0$ & $-1,2$ \\
\hline 018 & 10,5 & 8,7 & $-1,8$ & 10,8 & 10,5 & $-0,3$ & $-0,3$ & $-1,8$ & $-1,5$ \\
\hline 019 & 12,0 & 11,5 & $-0,5$ & 12,3 & 12,9 & 0,6 & 0,6 & $-1,4$ & $-2,0$ \\
\hline 020 & 10,0 & 9,9 & $-0,1$ & 12,5 & 12,8 & 0,3 & 0,3 & $-2,9$ & $-3,2$ \\
\hline Média & 11,2 & 9,8 & $-1,4$ & 11,2 & 10,4 & $-0,8$ & 0,2 & $-0,7$ & $-0,8$ \\
\hline Mediana & 11,7 & 10,0 & $-1,6$ & 10,9 & 10,5 & $-0,5$ & 0,2 & $-0,7$ & $-1,1$ \\
\hline Mínimo & 7,7 & 8,1 & $-3,3$ & 8,1 & 7,5 & $-2,4$ & $-2,8$ & $-2,9$ & $-3,2$ \\
\hline Máximo & 13,1 & 11,5 & 0,4 & 13,6 & 12,9 & 0,6 & 2,7 & 1,5 & 1,1 \\
\hline Erro Padrão & 0,3 & 0,3 & 0,2 & 0,3 & 0,4 & 0,2 & 0,3 & 0,3 & 0,2 \\
\hline IC de $95 \%$ & $\begin{array}{l}10,5 ; \\
11,9]\end{array}$ & {$[9,2 ; 10,4]$} & {$[-1,9 ;-1]$} & $\begin{array}{l}10,5 ; \\
11,9]\end{array}$ & {$[9,7 ; 11,2]$} & $\begin{array}{c}{[-1,16} \\
-0,4]\end{array}$ & {$[-0,7 ; 0,7]$} & $\begin{array}{l}-1,2 ; \\
-0,08]\end{array}$ & {$[-1,1 ;-0,2]$} \\
\hline \multicolumn{9}{|c|}{$\Delta(\%)$ em relação ao controle } & $-5,4$ \\
\hline \multicolumn{9}{|c|}{ \% de participantes com redução } & 73,7 \\
\hline \multicolumn{9}{|l|}{ P-Valor } & 0,011* \\
\hline
\end{tabular}

*** significativo ao nível de $0,1 \%$;**ignificativo ao nível de $1 \%$; *significativo ao nível de $5 \%$ (teste t de Student). 


\section{ANÁLISE SENSORIAL}

No âmbito geral, a opinião sobre o produto foi classificada como "ótima" e as notas variaram entre 9 e 10, como apresentadas na Tabela 12. Além disso, os usuários relataram que o produto oferecia excelente absorção, visto que, ao ser aplicado possui toque sensorial agradável. Alguns relatos dos colaboradores são apresentados, a seguir:

- "Diminuiu o suor das mãos. Ao usar o produto juntamente com a luva, não houve incômodos usuais. Assim, não há a necessidade de trocar a luva várias vezes ao dia." - relato do usuário;

- “Auxiliou na cicatrização de pequenos cortes inflamados"- relato do usuário;

- "Hidratou muito as mãos." - relato do usuário.

A análise sensorial realizada com os colaboradores das empresas mostrou que o creme protetor apresenta qualidade aos quesitos avaliados, destacando, principalmente, a hidratação, espalhabilidade, absorção, aspecto sensitivo e o perfume. Além dos resultados de melhoria da saúde da pele dos colaboradores participantes, eles relataram melhorias no bem-estar pessoal. Tal fato justifica o investimento em creme que realmente comprove a eficácia e a segurança para o tratamento de dermatoses ocupacionais que são, ainda, negligenciadas no país e no mundo.

Tabela 12. Resultado da Avaliação feita pelos Colaboradores das empresas após aplicação do creme protetor.

\begin{tabular}{|c|c|c|c|c|c|}
\hline Parâmetro & $\begin{array}{c}\text { Nota } \\
\text { Usuário 1 }\end{array}$ & $\begin{array}{c}\text { Nota } \\
\text { Usuário 2 }\end{array}$ & $\begin{array}{c}\text { Nota } \\
\text { Usuário 3 }\end{array}$ & $\begin{array}{c}\text { Nota } \\
\text { Usuário 4 }\end{array}$ & $\begin{array}{c}\text { Média } \\
\text { de notas }\end{array}$ \\
\hline Espalhabilidade & 10 & 10 & 10 & 10 & 10 \\
\hline Hidratação & 10 & 10 & 10 & 10 & 10 \\
\hline Absorção & 10 & 10 & 10 & 10 & 10 \\
\hline $\begin{array}{c}\text { Sensorial de } \\
\text { Aplicação }\end{array}$ & 10 & 10 & 10 & 10 & 10 \\
\hline $\begin{array}{c}\text { Recuperação das } \\
\text { fissuras após 24h }\end{array}$ & 10 & 8 & 5 & 10 & 8,25 \\
\hline $\begin{array}{c}\text { Recuperação das } \\
\text { fissuras após 48h }\end{array}$ & 10 & 9 & 6 & 10 & 8,75 \\
\hline $\begin{array}{c}\text { Recuperação das } \\
\text { fissuras após 72h }\end{array}$ & 10 & 10 & 7 & 10 & 9,25 \\
\hline $\begin{array}{c}\text { Recuperação das } \\
\text { fissuras após 96h }\end{array}$ & 10 & 10 & 8 & 10 & 9,5 \\
\hline $\begin{array}{c}\text { Perfume do } \\
\text { Produto }\end{array}$ & 10 & 10 & 10 & 10 & 10 \\
\hline
\end{tabular}

\section{Conclusão}

De acordo com os resultados de todos os testes realizados, foi possível concluir que o creme protetor apresenta todas as características necessárias para ser apresentado ao mercado consumidor como um produto inovador e de qualidade. Os ensaios de comprovaram que o Creme Protetor não é alergênico, não é irritante e é classificado com Grupo 3/especial, ou seja, resistente a óleo, à água e a outros produtos testados. Mesmo com as alterações indetificadas na densidade e na perda de água, justificada pela formulação inovadora, o produto está apto a ser produzido, vendido e consumido de acordo com a NBR 16276 e ANVISA, que determina os padrões de qualidade e eficácia para os cremes de proteção. O teste de análise sensorial apresentado revela que o produto não teve apenas melhora na saúde da pele dos colaboradores participantes, mas também no bem-estar piscicológico. Demostrou, portanto, eficiência, segurança e praticidade em relação aos cremes protetores convencionais devido a formualção aerossol.

\section{Agradecimentos}

$\mathrm{O}$ creme protetor foi desenvolvido em parceria do Instituto SENAI de Tecnologia em Alimentos e Bebidas, Goiânia, Goiás, Brasil e com a empresa Parceira. Apoio do Edital Senai Sesi Inovação (2015).

\section{Referências}

1. Ali, S. A. Dermatoses ocupacionais. São Paulo: FUNDACENTRO/ FUNDUNESP, 2001, 223.

2. Almeida, I. F.; Gaio, A. R.; Bahia, M. F. Hedonic and descriptive skinfeel analysis of two oleogels: comparison with other topical formulations. J Sens Stud. 2008.

3. Associação Brasileira de Normas Técnicas. NBR 16276: Cremes protetores de segurança contra agentes químicos- Requisitos e métodos de ensaio. Rio de Janeiro, 2017.

4. Aust, L. B.; Oddo, L. P.; Wild, J. E.; Mills, O. H. Deupree, J. S. The descriptive analysis of skin care products by a trained panel of judges. $\mathrm{J}$ Soc Cosmet Chem. 1987, 38, 443-48.

5. Bacle, I.; Meges, S.; Lauze, C.; Macleod, P.; Dupuy, P. Sensory analysis of four medical spa spring waters containing various mineral 
concentrations. Int J Dermatol. 1999, 38, 784-86.

6. Brasil. Guia de estabilidade de produtos cosméticos. Órgão emissor: ANVISA - Agência Nacional de Vigilância Sanitária. Brasília, 2014.

7. Brasil. Guia para avaliação da segurança de produtos cosméticos. Órgão emissor: ANVISA - Agência Nacional de Vigilância Sanitária. 2003.

8. Brasil. Resolução RDC nº 481, de 23 de setembro de 1999. Estabelece os parâmetros de controle microbiológico para os produtos de higiene pessoal, cosméticos e perfumes. Órgão Emissor: Agência Nacional de Vigilância Sanitária ANVISA, 27 de set. de 1999.

9. Brito, A. S. R. Manual de ensaios toxicológicos in vitro. Editora da UNICAMP, Campinas, São Paulo, 1994.

10. Brown, T. Strategies for prevention: occupational contact dermatitis. Occupational Medicine. 2004, 54, 450-457.

11. Conselho Nacional de Saúde. Resolução n. 466 de 12 de dez. de 2012. Aprova as diretrizes e Normas Regulamentadoras de pesquisas envolvendo seres humanos. 2012.

12. Corazza, M. Barrier creams: facts and controversies. Dermatitis. 2014, $25,327-333$

13. Farmacopeia Brasileira, 5.ed. São Paulo: Atheneu, 2010.

14. Fernandez O, Canosa JM, Lazzarini R, Duarte I. Associação de urticária de contato e dermatite alérgica de contato com borracha. An Bras Dermatol. 2009;84:177-9. 7.

15. Hutchings CV, Shum KW, Gawkrodger DJ. Occupational contact dermatitis has an appreciable impact on quality of life. Contact Dermatitis. 2001;45:17-20.

16. Instituto Nacional de Controle de Qualidade e Saúde. Manual da qualidade: ensaio de irritação cutânea primária. Rio de Janeiro. 2001, 15.

17. Isaac, V. L. B.; Cefali, L. C.; Chiari, B. G.; Oliveira, C. C. L. G.; Salgado, H. R. N.; Correa, M. A. Protocolo para ensaios físicoquímicos de estabilidade de fitocosméticos. Rev Cienc Farm Básica Apl. 2008, 29, 85-100.

18. Lee, I. S.; Yang, H. M.; Kim, J. W.; Maeng, Y. J.; Lee, C. W.; Kang, Y. $\mathrm{S}$. Terminology development and panel training for sensory evaluation of skin care products including aqua cream. J Sens Stud. 2005, 20, 421-33.

19. Mahmoud, G.; Lachapelle, J. M.; Neste, D. Histological assessment of skin damage by irritants: it's possible use in the evaluation of a 'barrier cream'. Contact Dermatitis. 1984, 11, 179-185.

20. Mendes, R. Patologia do trabalho. Atheneu, 2003, 2, 1444-1454.

21. Meding B, WrangsjoK, Jarvholm B. Fifteen-year follow-up of hand eczema: persistence and consequences. Br J Dermatol. 2005;152:975-80.

22. Montagner, Divanéia, Corrêa, Giane Márcia. Stability evaluation of cream with different pHs in urea. Rev. Bras. Farm., 85(3): 69-72, 2004

23. Mostosi, C.; Simonart, T. Effectiveness of barrier creams against irritant contact dermatitis. Dermatology. 2016, 232, 353-362.

24. Muñoz, A. M.; Civille, G.V.; Carr, B.T. Sensory evaluation in quality control. New York: Van Nostrand Reinhold. 1993, 240.
25. Parente, M. F.; Gambaro, A; Solana, G. Study of sensory properties of emollients used in cosmetics and their correlation with physicochemical properties. J Cosmet Sci. 2005, 56, 175-82.

26. Rogiers, V.; Balls, M.; Basketter, D.; Berardesca, E.; Edwards, C.; Elsner, $\mathrm{P}$. The potential use of non-invasive methods in the safety assessment of cosmetic products - The report and recommendations of an ECVAM/EEMCO. ATLA. 1999, 27, 515-537.

27. Santos, H. Toxicologia: a garantia de cosméticos seguros. Cosmet Toilet. 2008; 20, 20-4.

28. Secretaria de Segurança e Saúde do Trabalhador. Portaria n. 26 de dez. de 1994. Classifica os Cremes Protetores como Equipamento de proteção Individual (EPI), com sua inclusão da Norma Regulamentadora. 1994.

29. Secretaria de Segurança e Saúde do Trabalhador. Portaria n. 452 de 20 de nov. de 2014, Anexo II. Normas Técnicas aplicáveis aos EPI. 2014.

30. Silva Júnior. Obtenção e avaliação de forma farmacêutica semi-sólida fitoterápica contendo extrato seco por nebulização de Simphytum officinale L. (confrei). São Paulo, Tese de doutorado, Programa de Pós graduação em Fármacos e Medicamentos, Universidade de São Paulo, 2006.

31. Wortel, V. A.; Wiechers, J. W. Skin sensory performance of individual personal care ingredients and marketed personal care products. Food Qual. Pref. 2000, 11, 121-27.

32. Zhai, H. Maibach, H. I. Barrier creams skin protectants: can you protect skin? J Cosmet Dermatol. 2002, 1, 20-23.

33. Zur Mühlen, A.; Klotz, A.; Allef, P.; Weimans, S.; Veeger, M.; Thörner, B.; Eichler, J. O. Using skin models to assess the effects of a pre-work cream. Methodological aspects and perspective of the industry. Curr Probl Dermatol. 2007, 34, 19-32.

\section{Nathalia P. Barbosa*, Giselle V. G. Lopes, Patrícia de A. Moreira, Adriana A. de Carvalho \& Christiane S. Almeida}

Instituto SENAI de Tecnologia em Alimentos e Bebidas. Escola SENAI Vila Canaã. Rua Professor Lázaro Costa 348, Vila Canaã, CEP 74.415-420, Goiânia, Goiás, Brasil.

*E-mail: istvilacanaa@sistemafieg.org.br 